\title{
El papel de la mujer investigadora en México
}

\author{
The role of women researchers in Mexico
}

\author{
Laura Cortés Sanabria, * Juan Carlos Ayala Cortésł
}

*Dirección de Educación e Investigación en Salud, Unidad Médica de Alta Especialidad, Hospital de Especialidades, Centro Médico Nacional de Occidente, Instituto Mexicano del Seguro Social, Guadalajara, México; ¥Escuela de Física, Centro Universitario de Ciencias Exactas, Universidad de Guadalajara, Guadalajara, México.

\section{Introducción}

De acuerdo con la Real Academia Española, la ciencia se refiere al conjunto de conocimientos obtenidos mediante la observación y el razonamiento, sistemáticamente estructurados y de los que se deducen principios y leyes generales con capacidad predictiva y comprobables experimentalmente. ${ }^{1}$ Es a través de la generación de la ciencia que se interpretan los hechos de la naturaleza que requieren de una explicación científica.

La ciencia ha sido parte fundamental de la actividad humana desde la aparición de la especie, ha hecho posibles grandes beneficios para la humanidad y las mujeres siempre han desempeñado un papel esencial en este proceso desde tiempos remotos. Sin embargo, a pesar de ello, la perspectiva de la presencia histórica de las mujeres como generadoras de ciencia sigue siendo virtualmente desconocida. La autora Margarita Alic, en su obra «El legado de Hipatia: Historia de las mujeres en la ciencia desde la antigüedad hasta fines del siglo XIX», establece que la historia de la ciencia siempre ha sido concebida como una historia de hombres, y aún más, se concibe como una historia de pocos hombres (Aristóteles, Copérnico, Newton, Einstein). ${ }^{2}$ Sin embargo, estamos de acuerdo con la autora, en el sentido de que en la historia de la ciencia, millares de personas han contribuido a la generación de conocimiento científico, así como de enormes beneficios al mundo a través de sus descubrimientos. ${ }^{2}$ Definitivamente muchas de esas personas fueron mujeres, entre ellas Marie Curie quien empezara a descubrir los misterios de la

Correspondencia:

Laura Cortés Sanabria

E-mail: cortes_sanabria@yahoo.com.mx radioactividad cambiando para siempre no sólo nuestra comprensión del universo físico, sino también la estructura de la investigación científica y la situación de las mujeres de ciencia.

La perspectiva de las mujeres como productoras del conocimiento en el campo científico hoy en día es más valorada y se reconoce el papel de la mujer en la ciencia, gracias a la dedicación, el trabajo duro y el compromiso que le otorgan a su disciplina y quehacer científico. Sin embargo, sigue siendo insuficiente. Las estadísticas a nivel mundial reportan que menos de $30 \%$ de los científicos en el mundo son mujeres, ${ }^{3}$ en Europa $41 \%{ }^{4}$ y en Estados Unidos $20 \%$. Además, los premios nobel en química, física, fisiología y medicina han sido obtenidos por 599 hombres, frente a las 17 mujeres que lo han logrado. De hecho, en 2018 los premiados fueron nueve científicos, un economista, un escritor y un grupo de una organización no gubernamental. ${ }^{3}$

Resulta verdaderamente complicado nombrar a cada una de las mujeres que durante la historia de la humanidad han aportado a la ciencia, tecnología e innovación. Por lo que en la Tabla 1 se muestran sólo algunos ejemplos de algunas de ellas en representación de todas las mujeres que han contribuido al progreso y avance de la ciencia en el mundo.

La ciencia y la igualdad de género son fundamentales para el desarrollo sostenible de la innovación y la tecnología. La UNESCO reporta que sólo uno de cada cinco países ha logrado la equidad de género en la investigación, también se ha confirmado que las mujeres tienen salarios menores que los hombres en posiciones similares, los cargos con mayor responsa- 


Científica Contribución

\section{Ada Lovelace (1815-1852)}

Nació en Londres, Inglaterra. Estudió con tutores privados enfocados

en ciencias, lógica y matemáticas

\section{Marie Curie (1867-1934)}

Nacida en Varsovia, nacionalizada francesa. Física y química, pionera en el campo de la radioactividad, fue la primera persona en recibir dos premios noveles de distintas especialidades (física y química). También fue la primera mujer en ocupar el puesto de profesora en la Universidad de París

\section{Lise Meitner (1878-1968)}

Nacida en Austria, fue de las primeras mujeres en obtener un doctorado en física

\section{Gerty Cori (1896-1957)}

$(0)$

Estudió medicina en su país natal, Praga. Después de vivir por dos

años en Viena, Austria (donde no le permitieron trabajar como académi-

ca por ser muier) se mudó a Estados Unidos donde pudo trabajar como

investigadora en Búfalo, NY.

\section{Nettie Stevens (1861-1912)}

Nació en Vermont, Estados Unidos. A los 39 años salió de Stanford con su maestría terminada. Se doctoró en el Bryan Mawr College de Filadefia, Pensilvania, en donde se encontraban dos de los grandes biólogos de la época (Edmundo B Wilson y Thomas H. Morgan). La influencia de ambos fue decisiva en su carrera como genetista investigadora

\section{Grace Hopper (1906-1992)}

Conocida como la madre de la computación, Grace nació en Nueva York, donde ostudió matemáticas y física. Después de obtener dos títulos en estas áreas obtuvo un doctorado en matemáticas. Cuando Estados Unidos se unió a la segunda guerra mundial Grace fue aceptada en la reserva naval estadounidens

\section{Rita Levi-Montalcini (1909-2012)}

Se graduó en 1936 en la escuela de medicina en Turín, Italia. No pudo seguir estudiando ya que durante la dictadura de Mussolini no se ermitió seguir con sus estudios o investigaciones al ser jud permí in siguió investigando en su casa con embriones de pollos y equipo caUnidos, donde siguió con sus estudios en embriones
En 1842 realizó su único trabajo profesional. La revista Scientific Memoirs le encargó la traducción de un artículo escrito en francés en el que se describía la «máquina analítica de Charles Babbage». A sugerencia de este último, Ada publicó el artículo acompañándolo de un nutrido apartado de notas donde explicaba sus propias ideas sobre el funcionamiento de la máquina. Estas notas, firmadas sólo con sus iniciales AAL para ocultar su identidad femenina, son consideradas hoy en día el primer lenguaje de programación

En 1910, junto con su esposo Pierre Curie, aislaron el radio en su estado puro. Publicaron trabajos científicos, entre ellos el que anunciaba que cuando el ser humano se expone al radio las células malignas y formadoras de neoplasias eran destruidas más rápido que las células sanas. En 1903, la Real Academia de las Ciencias en Suecia galardon a Marie Curie con el premio Nobel de física junto a su marido y Hen Becquerel. Al principio, el comité seleccionador pretendía honrar solamente a Pierre y Henri, negando entregar el reconocimiento a Marie por ser mujer. Sin embargo, al negarse su marido a acudir a recibir e premio, el comité aceptó finalmente la participación de Marie Curie

Lise descubrió la fisión nuclear, proceso que ocurre al detonar una bomba nuclear

En 1947 Gerty y su esposo fueron galardonados con el premio Nobe de Fisiología y Medicina por su trabajo sobre el almacenamiento y liberación de glucosa en el cuerpo (ciclo de Cori)

Descubrió que el sexo está determinado por los cromosomas. Constató que siempre vienen en pares, que las hembras tienen dos cromosomas $X X$ mientras que los hombres tienen cromosomas $X Y$ y que el
cromosoma $X$ es heredado de la madre, pero el padre puede dar tanto cromosomas $X$ como $Y$

Trabajó en el proyecto Mark I, una de las primeras computadoras. Estaba diseñada para calcular la trayectoria de las armas de los buques de guerra. En 1949 comenzó a trabajar en UNIVAC I, la primera computadora electrónica comercial. También desarrolló el primer compilador

En 1995 escribió Flow-Matic, el primer lenguaje de computadora que utilizaba palabras en inglés y francés en lugar de símbolos matemáticos complejos. Fue la base para la creación del Cobol, que en 1970 era el lenguaje computacional más utilizado en el mundo

Descubrió la proteína que controla el crecimiento nervioso y ganó el Nobel de 1986 junto con su compañero Stanley Cohen

También fue galardonada como miembro de la Organización Europea de Biología Molecular (EMBO) y senadora de por vida en el gobierno italiano, donde trabajó hasta su muerte a los 103 años
Frase celebre

Mi cerebro es algo más que meramente mortal, el tiempo lo demostrará,

No debemos olvidar que cuando se descubrió el radio nadie sabía que iba a ser útil en hospitales. Era un trabajo de ciencia pura. Y ello es prueba de que el trabajo científico no debe considerarse desde el punto de vista de su uso directo. Se debe realizar por sí mismo, por la belleza de la ciencia y luego siempre existirá la posibilidad de que un descubrimiento científico se convierta, como el radio, en un beneficio para la humanidad"

L ciencia hace a la gente tratar de luchar desinteresadamente para Ulegar a la verdad y la objetividad

"Creo que el arte y la ciencia son glorias de la mente humana. No veo conflicto entre ellas

"Los humanos son alérgicos al cambio, les encanta decir: siempre lo hemos hecho de esta manera. Intento luchar contra esto. Por eso yo

tengo un reloj en mi pared con las manecillas moviéndose contrarreloj

todo, no temas a los momentos difíciles. Lo mejor viene de 
Continúa la Tabla 1: Mujeres que han contribuido al progreso y avance de la ciencia en el mundo. ${ }^{5}$

\begin{tabular}{|c|c|c|}
\hline Científica & Contribución & Frase celebre \\
\hline $\begin{array}{l}\text { Chien-Shiung Wu (1912-1997) } \\
\text { Física estadounidense, nacida en China experta en radioactividad } \\
\text { Se graduó de la Universidad Nacional Central de Nanjing con las } \\
\text { mejores calificaciones } \\
\text { Completó su doctorado en Estados Unidos } \\
\text { En } 1945 \text { se convirtió en profesora en la Universidad de Columbia }\end{array}$ & $\begin{array}{l}\text { Trabajó en el proyecto Manhattan, donde contribuyó a desarrollar el } \\
\text { proceso de separar el uranio metálico en isótopos de uranio-235 y } \\
\text { uranio-238 mediante difusión gaseosa. Dirigió el experimento Wu, en el } \\
\text { que se refuta la ley de la conservación de la paridad } \\
\text { Sus aportaciones en física experimental fueron tan importantes que fue } \\
\text { comparada con la química y física Marie Curie, y se le apodó como «la } \\
\text { primera dama de la física» o «la reina de la investigación nuclear» }\end{array}$ & $\begin{array}{l}\text { "iEstos fueron momentos de euforia y éxtasis! Un vistazo de esta } \\
\text { maravilla puede ser la recompensa de toda una vida. ¿Podría ser que } \\
\text { la emoción y los sentimientos ennoblecedores como estos nos hayan } \\
\text { mantenido a los científicos avanzando para siempre?» }\end{array}$ \\
\hline \multirow{2}{*}{$\begin{array}{l}\text { Hedy Lamar (1914-2000) } \\
\text { Nacida en Viena, Austria. Durante la segunda guerra mundial su esposo } \\
\text { traficaba armas a nazis y fascistas judíos lo que hizo que Hedy se divor- } \\
\text { ciara de él, ya que ella tenía raíces judías. Después de abordar un barco } \\
\text { a Estados Unidos formó parte de varias películas de gran presupuesto }\end{array}$} & $\begin{array}{l}\text { A los } 27 \text { años, junto con un amigo compositor idearon un sistema segu- } \\
\text { ro para que los buques de guerra controlen sus torpedos, un precursor } \\
\text { del GPS, WiFi y sistemas Bluetooth }\end{array}$ & \multirow[t]{2}{*}{ "Todas las personas creativas quieren hacer algo inesperado" } \\
\hline & $\begin{array}{l}\text { En 1995, a los } 80 \text { años, su trabajo fue reconocido con el Bulbi Gnass } \\
\text { Spirit of Achievement }\end{array}$ & \\
\hline \multirow{2}{*}{$\begin{array}{l}\text { Sylvia Earle (1935-) } \\
\text { Bióloga marina, exploradora y primera científica jefe de la Administra- } \\
\text { ción Nacional Oceánica y Atmosférica. A los } 12 \text { años, Sylvia se mudó } \\
\text { al Golfo de México donde vivió en cercanía con el océano. En } 1953 \\
\text { comenzó a bucear y poco después completó dos títulos universitarios } \\
\text { en botánica, llevando a cabo una extensa investigación sobre algas, lo } \\
\text { que tomó un periodo de } 10 \text { años, con lo que logró obtener su doctorado }\end{array}$} & $\begin{array}{l}\text { Ha formado parte de juntas marítimas, dirigido más de } 50 \text { expedicio- } \\
\text { nes, publicado más de cien artículos científicos y varios libros sobre la } \\
\text { protección de los océanos del mundo }\end{array}$ & \multirow[t]{2}{*}{$\begin{array}{l}\text { "Aun si nunca tienes la oportunidad de ver o tocar el océano, el océano } \\
\text { te toca cada vez que respiras, en cada gota de agua que tomas y con } \\
\text { cada bocado que comes" }\end{array}$} \\
\hline & $\begin{array}{l}\text { Es cofundadora de una empresa submarina. Diseñó el Deep Rover, } \\
\text { un submarino de investigación para una persona capaz de descender } \\
1,000 \text { metros al lecho marino y fundó la organización Mission Blue con } \\
\text { el objetivo de crear zonas protegidas en el océano }\end{array}$ & \\
\hline \multirow[t]{2}{*}{$\begin{array}{l}\text { Valentina Tereshkova (1937-) } \\
\text { La infancia de Valentina no fue fácil, después de que su padre muriera en } \\
\text { la segunda guerra mundial, ella y sus dos hermanos tuvieron que dejar la } \\
\text { escuela para trabajar en la misma fábrica que su madre. Valentina siguió } \\
\text { estudiando gracias a cursos de aprendizaje a distancia. Su pasión era el } \\
\text { paracaidismo, lo que le permitió entrar al programa espacial soviético }\end{array}$} & $\begin{array}{l}\text { Con su experiencia en paracaidismo fue aceptada para la primera } \\
\text { misión para llevar a una mujer al espacio. En 1963, permaneció en el } \\
\text { espacio durante } 48 \text { horas dándole la vuelta a la Tierra } 48 \text { veces, gracias } \\
\text { a eso ahora es Héroe de la Unión Soviética y obtuvo la Medalla de la } \\
\text { Paz de las Naciones Unidas }\end{array}$ & \multirow[t]{2}{*}{$\begin{array}{l}\text { "Cualquiera que haya pasado algún tiempo en el espacio lo ama por el } \\
\text { resto de su vida. Yo logré lo que soñaba en mi infancia: el cielo" }\end{array}$} \\
\hline & Hoy en día un cráter lunar y un planeta llevan su nombre & \\
\hline $\begin{array}{l}\text { Ada Yonath (1939-) } \\
\text { Nacida en Jerusalén, Israel. Tuvo una infancia difícil al ser hija de } \\
\text { inmigrantes polacos. Aun así, logró continuar sus estudios y recibirse } \\
\text { como bioquímica }\end{array}$ & $\begin{array}{l}\text { En el año 2000, Ada y sus colegas demostraron que es posible tomar ra- } \\
\text { yos X a los átomos dentro de los ribosomas cuando se someten a tempe- } \\
\text { raturas muy bajas. Este trabajo fue muy importante para el desarrollo de } \\
\text { antibióticos, lo que les valió el premio Nobel de Química en el año } 2009\end{array}$ & "La ciencia es la fuerza del futuro» \\
\hline \multirow{3}{*}{$\begin{array}{l}\text { Margarita Salas Falgueras (1938-2019) } \\
\text { Científica bioquímica e investigadora española. En mayo de 2007, se } \\
\text { convirtió en la primera mujer española que forma parte de la Academia } \\
\text { Nacional de Ciencias de Estados Unidos } \\
\text { Alumna de Severo Ochoa, premio Nobel de Medicina de } 1959 \\
\text { Elizabeth Blackbrun (1948-) } \\
\text { Nacida en la isla de Tasmania, Australia. Estudió bioquímica en la Uni- } \\
\text { versidad de Melbourne y obtuvó su doctorado en Cambridge, Inglaterra }\end{array}$} & $\begin{array}{l}\text { Inició el desarrollo de la biología molecular en España. Entre sus } \\
\text { mayores contribuciones científicas destaca la determinación de la direc- } \\
\text { cionalidad de la lectura de la información genética, y el descubrimiento } \\
\text { y caracterización del ADN polimerasa del fago } 29 \text { que tiene múltiples } \\
\text { aplicaciones biotecnológicas debido a su altísima capacidad de amplifi- } \\
\text { cación del DNA, además fue poseedora de ocho patentes }\end{array}$ & $\begin{array}{l}\text { "La mujer ocupará en el mundo científico el puesto que le corresponda de } \\
\text { acuerdo con su capacidad, y no necesitaremos cuotas ni nada de eso" }\end{array}$ \\
\hline & Era, además, poseedora de ocho patentes & \\
\hline & $\begin{array}{l}\text { A principios de la década de los } 80 \text { descubrió la telomerasa, compuesto } \\
\text { que ralentiza el acortamiento de los telómeros, lo que le valió un premio } \\
\text { Nobel junto con sus compañeros Carol Greider y Jack Szostak }\end{array}$ & $\begin{array}{l}\text { "La biología a veces revela sus principios fundamentales a través de lo } \\
\text { que puede parecer al principio arcano y extraño" }\end{array}$ \\
\hline
\end{tabular}

Modificado de: Pingray MJ, Parejas A, Kenigstein C. Mujeres extraordinarias del mundo, Editorial DreamsArt, Naucalpan de Juárez. Edo. de México, 2020.5 
bilidad son ocupados por hombres. Es claro que las políticas establecidas para revertir estos resultados deben estar encaminadas hacia el empoderamiento equitativo del género en ciencia, tecnología e innovacion. ${ }^{6}$ Los países escandinavos han sido durante mucho tiempo líderes en materia de igualdad de género en ciencia.

En 2016, la Asamblea General de las Naciones Unidas decidió proclamar el 11 de febrero como el Día Internacional de la Mujer y la Niña en la Ciencia con el fin de lograr su acceso y participación plena y equitativa en la ciencia, para lograr la igualdad de género y el empoderamiento de ambos grupos. Reafirmando además que las mujeres tienen la capacidad de contribuir en forma decisiva al logro del desarrollo sostenible del país, así como su participación activa y efectiva en las políticas, programas y procesos de adopción de decisiones en materia de desarrollo sostenible a todos los niveles. ${ }^{7}$

\section{Las mujeres y la ciencia en México}

México tiene un importante número de mujeres dedicadas a la investigación científica con importantes aportes; sin embargo, también existe una gran disparidad en la distribución de investigadores por género y área geográfica. Según el padrón del Sistema Nacional de Investigadores (SNI), sólo 38\% del total de los investigadores son mujeres. Si bien esta cifra es mayor que en algunos países desarrollados como Japón, en donde únicamente $15 \%$ de los investigadores son mujeres, existe un largo camino para lograr la paridad de género que se observa en países como Argentina, en el que las mujeres representan 53\% de la comunidad académica, según la OCDE. ${ }^{8}$ En la Tabla 2 se muestran algunos ejemplos de mujeres científicas mexicanas, aunque existen muchas más de las que aquí aparecen que han merecido y merecen el reconocimiento a su labor científica.

En México, en 2019 las personas calificadas como parte del acervo de recursos humanos en ciencia y tecnología fueron 16.8 millones, de las cuales 8.4 millones fueron mujeres, casi $50 \%$ del total (16.8 millones). Sin embargo, para no ocasionar confusión es importante señalar que no todas estas personas calificadas pertenecen al SNI. ${ }^{9}$

El flujo de personas que ingresan y egresan de estudios de maestría o doctorado constituye en el país una parte fundamental para responder a las exigencias y retos que la sociedad demanda en materia de ciencia, innovación y tecnología, aunque ahora no sólo importa la cantidad de ingresos o egresos en forma anual, sino también la disminución de la brecha de desigualdad por género a través del tiempo. En el año $2010,53 \%$ de los egresados de maestría fueron mujeres, observándose un crecimiento de 4\% en 2019 (57\%). Para el caso de las mujeres que egresaron de doctorado en 2010 correspondieron a 46\% mientras que en 2019 la proporción fue de 52\%. ${ }^{9}$

El número de miembros del SNI se ha incrementado ininterrumpidamente desde su creación el 26 de julio de 1984. En los recientes años, la matrícula de investigadores e investigadoras presentó un crecimiento significativo, ya que pasó de 18,555 miembros en 2012, a 30,548 en 2019 respectivamente (Figura 1). La tasa de crecimiento en este periodo fue de $64.63 \%$. Por su parte, la tasa de crecimiento promedio anual de 2012 a 2019 fue de $7.38 \% .^{9}$

En 2019, más de una tercera parte de los miembros del SNI fueron mujeres, quienes constituyen 38\% del total. Si se analizan estos datos desde 2012, el crecimiento de la participación de las mujeres en 2019 es notorio (81.4\%) (Figura 2) con un crecimiento anual de $8.7 \%$; no obstante, aún es insuficiente en materia de paridad de género ya que el crecimiento anual de hombres que recibieron la distinción como miembros del SNI fue de $15.5 \% .^{9}$

\section{Fuente Sistema Nacional de Investigadores (SNI)}

Dentro de los diferentes factores que durante la historia de la humanidad han limitado la accesibilidad de la mujer al campo de la ciencia, se encuentran la falta de acceso a la educación y/o a ciertos campos educativos que se consideraban exclusivos del hombre, debido a que la consideraban no capacitada para realizar esas actividades profesionales, afortunadamente hoy en día esta situación se ha sido superando. Por otra parte, también ha influido el sentimiento de inferioridad por nacer mujer y el ser dominada por el hombre, al considerarla como un modelo de delicadeza y debilidad, crear estereotipos sociales donde la mujer siempre ha tenido un papel dedicado al ámbito del hogar, además, una escasa visualización de la mujer científica, las niñas no se ven reflejadas cuando están estudiando en una científica a la cual pueden llegar a parecerse debido a que no existen este tipo de mujeres brillantes como referentes en los libros de texto, prefieren mejor ser modelos o youtubers porque es lo que observan con mayor frecuencia en la actualidad. 
Tabla 2: Mujeres destacadas en la Ciencia en México.

\author{
Científica \\ Ana Sofía Varela (1978-) \\ Forma parte del Departamento de Fisicoquímica del Instituto de Química, UNAM \\ Realizó una maestría en combustibles y energías para el futuro en Madrid, España \\ Recibió un reconocimiento por parte de la Organización de la Naciones Unidas para la Educación, la Ciencia \\ y la Cultura (UNESCO) \\ Ali Guarneros Luna (Ciudad de México, 1973-) \\ Ingeniera aeroespacial. Estudió ingeniería aeroespacial en la Universidad Estatal de San José, California. De- \\ sarrolló una pasantía en la NASA y actualmente colabora con la oficina de Sistemas de Seguridad y Garantía \\ de Misiones de la NASA en el Centro de Investigación Ames en Silicon Valley, CA, USA \\ Antígona Segura Peralta (Ciudad de México, 1971-) \\ Doctora en Ciencias de la Tierra \\ Investigadora en el Instituto de Ciencias Nucleares de la UNAM, colaboradora del Instituto de Astrobiología \\ de la NASA

\section{Eva Ramón Gallegos} \\ Doctora en Ciencias Químico-biológicas por el Instituto Politécnico Nacional (IPN) \\ Científica de la Escuela Nacional de Ciencias Biológicas del IPN \\ Líneas de investigación: ciencias biomédicas y nano-biotecnología \\ Mayra de la Torre Martínez (Ciudad de México, 1951) \\ Ingeniera Bioquímica por el INP \\ Maestría y Doctorado en la escuela Nacional de Ciencias Biológicas \\ Estudios Postdoctorales en el Instituto de Biotecnología de Instituto Suizo Federal de Tecnología. Ha colab- \\ orado con la Dirección de Ciencia y Tecnología de la Organización de los Estados Americanos (OEA) en el \\ programa de "Biotecnología/Bioseguridad para las Américas». Es miembro del Comité Ejecutivo de la Third \\ World Organization for Women in Science \\ Ana María López Colome (Ciudad de México, 1944-) \\ Bióloga con doctorado en bioquímica egresada de la UNAM. Es una de las investigadoras mexicanas más \\ distinguidas en el área de la Biología Experimenta \\ Sus contribuciones en el campo de la neuroquímica la han llevado a obtener galardones como el Premio \\ Mujeres en la Ciencia de L'Oreal-UNESCO, en 2002 \\ Julieta Norma Fierro Gossman (Ciudad de México, 1948-) \\ Física, astrofísica, UNAM \\ Investigadora del Instituto de Astronomía de la UNAM \\ Silvia Torres Castilleja (Ciudad de México, 1940-) \\ Astrónoma egresada de la Facultad de Ciencias de la UNAM. Doctorado de Astronomía por la Universidad de \\ California, Berkley, Estado Unidos. Directora del Instituto de Astronomía de la UNAM, presidenta de la Unión \\ Astronómica Internacional \\ Victoria Chagoya (Oaxaca, 1933-) \\ Química farmacéutica y bióloga, UNAM \\ Primera generación del Doctorado en Bioquímica de la UNAM \\ Estancia en la Universidad de Wisconsin, USA \\ Isaura Meza Gómez-Palacio (Ciudad de México, 1942-) \\ Bióloga del Centro de Investigación y Estudios Avanzados del IPN \\ Doctorado en Ciencias por la Universidad de Berkeley
}

\section{Contribución}

Su línea de investigación es la electrocatálisis, es decir, utilizar energía eléctrica para generar reacciones químicas. Su trabajo científico ha estado relacionado con el desarrollo de nuevos materiales para acelerar reacciones químicas que permiten transformar el dióxido de carbono en materiales no contaminantes como combustibles sustentables y compuestos que puedan servir para la industria química

Se especializa en el desarrollo de cohetes suborbitales y satélites de órbita inferior, además de tecnología como sensores, minisatélites, radios, materiales, que ayudarán a las futuras misiones a Marte

Fue parte del equipo que construyó el primer satélite americano lanzado desde la Estación Espacial Internacional

Sus estudios sobre bioseñales en planetas habitables alrededor de estrellas enanas M reabrieron el debate sobre la habitabilidad de los planetas que giran alrededor de este tipo de estrellas y han sido utilizados para roumer a la actividad cromosférica de las enanas $\mathrm{M}$.

Participa activamente en la búsqueda de tratamientos no invasivos para la erradicación del cáncer cervicouterino y sus lesiones premalignas producidas por el virus del papiloma humano (VPH) utilizando terapias fotodinámicas

Se ha especializado en la ingeniería de bioprocesos y en las fermentaciones, así como en la relación de los alimentos y los bioinsecticidas con ayuda de microorganismos y nematodos entomopatógenos, las señales de comunicación célula-célula y cascadas de transducción de señales en la bacteria Bacillus thuringiensis

Entre sus primeros proyectos colaboró para la industria azucarera mexicana buscando obtener subproductos del proceso de la caña de azúcar. Mediante investigaciones del bagazo y las melazas logró producir levadura alimenticia con un proceso de alto rendimiento. Desarrolló un proceso mejorado de la fermentación para producir proteína unicelular utilizando cualquier esquilmo agrícola que contenga celulosa o hemicelulosa Ha contribuido al esclarecimiento de los mecanismos de la neurotransmisión glutamatérgica en la retina. En este campo, es pionera en la caracterización bioquímica del proceso y se cuenta entre los primeros investigadores, a nivel mundial, en postular una función reguladora de la glia en transmisión sináptica. Esos hallazgos posibilitan el diseño de fármacos protectores específicos para las neuronas de la retina

Su trabajo de investigación se concentra en la materia interestelar, y sus trabajos más recientes se refieren al sistema solar. Sin embargo, su labor más destacada es la divulgación de la ciencia

Su investigación se ha centrado en la determinación de la composición química de las regiones de formación estelar y de los gases arrojados por las estrellas de masa intermedia en la vía láctea y otras galaxias, así como la determinación de la abundancia primordial de helio

Sus líneas de investigación fueron la caracterización y función del ciclo circadiano de la adenosina, hepatoxicidad aguda y crónica con etanol y tetracloruro de carbono, cirrosis y cáncer hepatocelular y cardiotoxicidad durante el infarto al miocardio experimental y la insuficiencia cardiaca

Investigó la estructura y caracterización de los genes de proteínas del citoesqueleto en modelos eucariontes como la amiba Entamoeba histolytica

Recientemente, ha estado estudiando cómo el citoesqueleto modula el cambio de la forma de células cancerosas no invasoras y cuáles son los mecanismos que inducen su modificación morfológica y funcional para convertirse en células metástasis. Cómo se organiza el citoesqueleto en neuronas de pacientes psiquiátricos las vías de señalización que están involucradas en ello, es otro de los temas con el que estamos trabajando 


\section{Estrategias para aumentar la participación de las mujeres en la ciencia, innovación y tecnología}

La escasa representación de las mujeres en la ciencia es una de las principales preocupaciones en relación con la igualdad entre hombres y mujeres, donde los tomadores de decisión o hacedores de políticas públicas deberán prestar especial atención. Por ejemplo, la política institucional de equidad de género en ciencia y tecnología 2017-2025 de Chile establece una serie de estrategias para garantizar el acceso y/o reconocimiento de las mujeres científicas en su país, entre las que destacan: ${ }^{10}$

1. Diagnóstico detallado de las principales barreras, brechas e inequidades de género en la ciencia y la tecnología. El diagnóstico se transforma en la justificación para la necesidad de contar con una política de género institucional y definir los principales objetivos estratégicos para incrementar la participación de la mujer en la generación de ciencia y tecnología.

2. Crear o fortalecer una política Institucional de Equidad de Género en Ciencia y Tecnología con el objetivo de transformar en áreas de oportunidad las barreras, brechas e inequidades de género en ciencia y tecnología.

3. Desarrollar un plan de acción anual que contempla metas, indicadores y acciones para alcanzar los objetivos definidos en la Política Institucional de Equidad de Género en Ciencia y Tecnología. El plan de

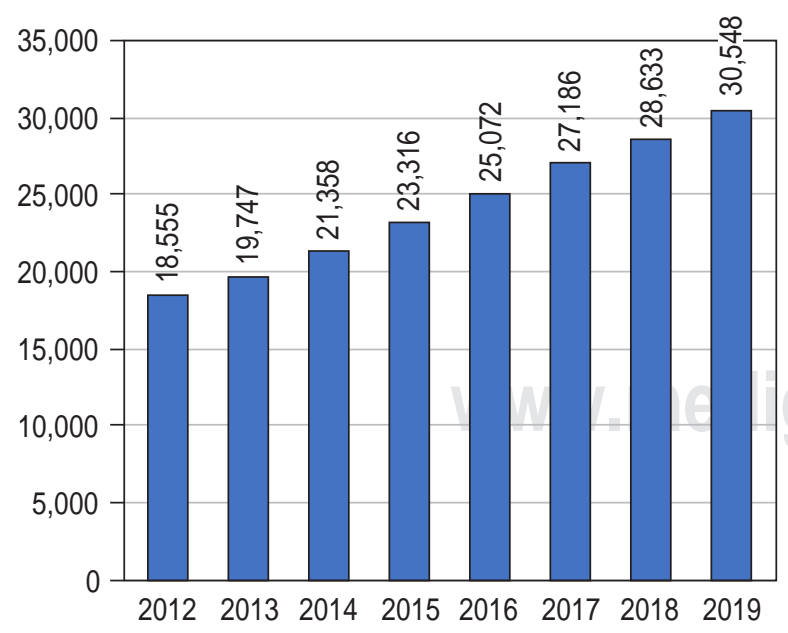

Figura 1: Número de miembros del Sistema Nacional de Investigadores, 2012-2019. Modificado de referencia 9.

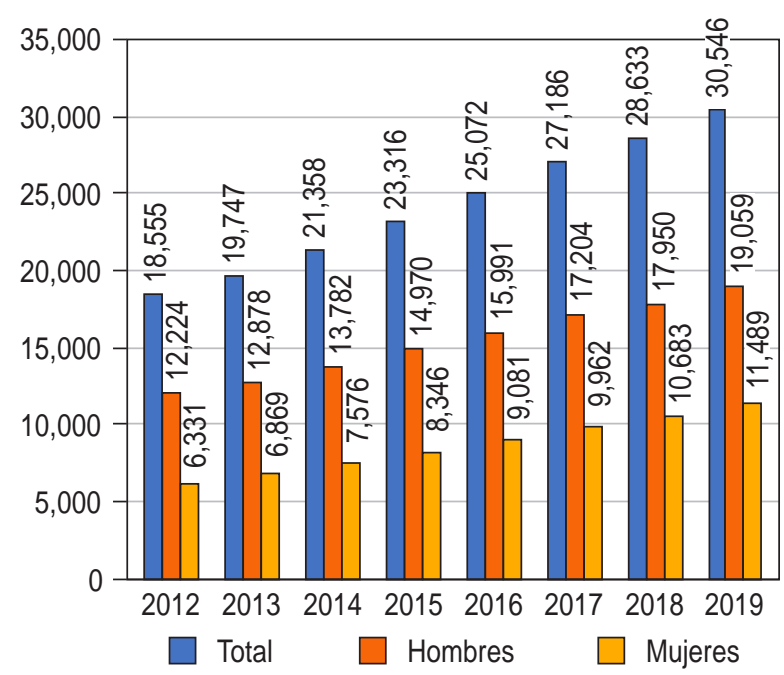

Figura 2: Distribución de los miembros del Sistema Nacional de Investigadores por género, 2012-2019. Modificado de referencia 9.

acción debe evaluarse cada año para establecer los cambios necesarios para el periodo siguiente que permitan plantear desafíos nuevos hacia el logro de los objetivos definidos en la política.

4. Sistema de Monitoreo y Seguimiento que permita evaluar el progreso y los resultados de la implementación del plan de acción.

5. Establecer estrategias permanentes de difusión y sensibilización de la implementación de una Política Institucional de Equidad de Género en Ciencia y Tecnología.

\section{Otras.}

En México, se requiere proponer acciones firmes que consoliden la participación de las mujeres científicas e investigadoras como promotoras del conocimiento e impulsoras de la innovación tecnológica del país. El Programa Especial de Ciencia, Tecnología e Innovación 2021-2024, del Consejo Nacional de Ciencia y Tecnología (CONACyT) ${ }^{8}$ establece las siguientes estrategias prioritarias: ${ }^{8}$

1. Reducir las brechas y las desigualdades regionales, de género y favorecer la inclusión y el acceso a la educación superior, los beneficios de la ciencia y la tecnología para alcanzar condiciones de equidad, justicia, desarrollo sustentable y bienestar de las mayorías del país.

2. Abatir la brecha de participación de las mujeres y de las mujeres indígenas en particular en el postgrado como elemento clave del desarrollo de ca- 
pacidades en las regiones con mayor índice de marginación

3. Implementar protocolos institucionales de atención a casos de violencia de género dentro de todo el sistema educativo, teniendo como principio la equidad, la no discriminación y con estricto apego a la ética.

4. Otras.

Las estrategias anteriores están alineadas al Plan Nacional de Desarrollo 2019-2024, donde se establece la responsabilidad del gobierno federal para promover la investigación científica y tecnológica; el apoyo a estudiantes y académicos con becas y otros estímulos en bien del conocimiento. Por otra parte, en este mismo plan de desarrollo se designa al CONACYT como ente coordinador para desarrollar y ejecutar el Plan Nacional para la Innovación en beneficio de la sociedad y del desarrollo nacional con la participación de universidades, pueblos, científicos y empresas. ${ }^{11}$

Para promover el reconocimiento de que la igualdad de género contribuya a mejorar la ciencia es fundamental evaluar la calidad de la investigación en lugar de la cantidad, establecer objetivos públicos explícitos y planes de acción para mejorar el equilibrio de género en las instituciones científicas, mejorar la visibilidad de las mujeres dentro de las instituciones y fomentar la diversidad en el estilo de liderazgo. ${ }^{12}$ Por otra parte, resulta necesario promover acciones para crear conciencia desde la educación primaria de que las niñas son capaces de estudiar lo que quieran, dar mayor visibilidad a las científicas mexicanas en las escuelas primarias a través de los libros gratuitos de texto, que las mujeres científicas den a conocer su trabajo no sólo a través de artículos científicos y/o que no se quede en los laboratorios, es decir, que sean más abiertas al público en general porque «lo que no se conoce no se valora», establecer canales de comunicación entre niñas y/o jóvenes con investigadoras y a su vez las investigadoras se acerquen a las escuelas para dar a conocer su trabajo científico y los niños se sientan atraídos por la ciencia. Por último, como lo establecía la científica española Margarita Salas desde el punto de vista político, no se deben asignar mujeres en la ciencia por cuota, las mujeres deben llegar porque lo merecen, porque han luchado para ello y porque no son menos capaces que los hombres.
Desafortunadamente, las nuevas generaciones no ven futuro en la ciencia y por eso se desaniman a pesar de que los expertos sostienen que el desarrollo económico y social de un país tiene mucho que ver con su potencial científico y tecnológico, con la capacidad de sus ciudadanos para investigar y llevar a la práctica, de forma continua, esos inventos, quizás por ello los gobiernos se deben esforzar en desarrollar políticas dirigidas a incrementar el gasto en investigación para tratar de sacar el máximo provecho a su potencial de desarrollo endógeno. Definitivamente, la competencia global del siglo XXI tendrá mucho que ver con esa especialización en gran escala.

\section{Referencias}

1. Real Academia Española. Disponible en: https://www.rae.es

2. Alic M. El legado de Hipatia" Historia de las mujeres en la ciencia desde la antigüedad hasta fines del siglo XIX. Disponible en: https://books.google.es/books?id=yFEdvT1।Qio C\&lpg=PA17\&ots=-CJutc5ly $7 \& d q=$ mujeres $\% 20$ en $\% 201 a \% 20 \mathrm{ci}$ encia\& $|r \& h|=e s \& p g=P A 16 \# v=0$ epage $\& q=$ mujeres $\% 20$ en $\% 20$ la\%20ciencia\& $f=f a l s e$

3. Investigación y Desarrollo. Disponible en: https://invdes. com.mx/politica-cyt-i/menos-del-30-de-los-investigadorescientificos-en-el-mundo-son-mujeres-segun-la-unesco/

4. Eurostat. Disponible en: https://ec.europa.eu/eurostat/web/ products-eurostat-news/-/edn-20210210-1

5. Pingray MJ, Parejas A, Kenigstein C. Mujeres extraordinarias del mundo, Editorial DreamsArt, Naucalpan de Juárez. Edo. de México, 2020.

6. UNESCO, Día Internacional de la Mujer y la Niña en la Ciencia. Disponible en: https://es.unesco.org/commemorations/ womenandgirlinscienceday

7. Resolución aprobada por la Asamblea General el 22 de diciembre de 2015, Día Internacional de la Mujer y la Niña en la Ciencia. Disponible en: https://www.un.org/en/ga/search/ view_doc.asp?symbol=A/RES/70/212\&Lang=S

8. Programa Especial de Ciencia, Tecnología e Innovación 2021-2024, CONACYT derivado del Plan Nacional de Desarrollo 2019-2024. Disponible en: https://www.siicyt.gob. $\mathrm{mx} /$ index.php/normatividad/nacional/programa-especial-deciencia-tecnologia-e-innovacion-peciti/programa-especialde-ciencia-tecnologia-e-innovacion-peciti-2021-2024/4965programa-especial-de-ciencia-tecnologia-e-innovacionpeciti-2021-2024/file

9. https://www.siicyt.gob.mx/index.php/estadisticas/informegeneral/informe-general-2019/4948-informe-general-2019/file

10. https://siteal.iiep.unesco.org/sites/default/files/sit_accion_ files/politica-institucional-equidad-de-genero-en-cytperiodo-2017_2025.pdf

11. Plan Nacional de Desarrollo 2019-2024. Disponible en: https:// lopezobrador.org.mx/wp-content/uploads/2019/05/PLANNACIONAL-DE-DESARROLLO-2019-2024.pdf

12. Promoting women in science and medicine. 2010 Available in: www.thelancet.com 